\title{
Brain Tumor Stem Cells and Immunotherapy
}

\author{
Isako Saga and Masahiro Toda*
}

\author{
Department of Neurosurgery, Keio University School of Medicine, Tokyo, Japan
}

\begin{abstract}
Glioblastoma multiforme (GBM) is one of the most common aggressive primary brain tumors, and it responds poorly to the current treatment combination of surgery, radio-, and chemotherapy. The hypothesis that cancer stem cells may account for the pathogenesis underlying various tumors, including GBM, has been accepted widely in recent years. Brain tumor stem cells (BTSCs) have been shown to contribute to therapeutic resistance and the presence of BTSCs may explain the recurrence of GBM following conventional treatment, as just a few BTSCs are sufficient to give rise to a new tumor. Therefore, the therapeutic targeting of BTSCs is of utmost importance. Among emerging treatment modalities, immunotherapy is a strategy that has the potential to target BTSCs that are resistant to conventional therapies. This review describes recent advancements in the study of BTSCs and immunotherapy.
\end{abstract}

Keywords: Glioma, glioblastoma, cancer stem cell, niche, immunoresistance, peptide vaccine, EGFRvIII, WT1, dendritic cell, SOX6.

\section{INTRODUCTION}

Glioblastoma multiforme (GBM) is the most lethal primary brain tumor with a median survival of 14.6 months, even with aggressive therapy including surgery, radio-, and chemotherapy, due to tumor invasion, frequent recurrence, and resistance to conventional therapies [1]. The cancer stem cell (CSC) hypothesis, first proposed in 1997, explains not only the cellular and genetic heterogeneity, but also the poor prognosis of GBM [2, 3]. A few brain tumor stem cells (BTSCs) capable of self-renewal, multilineage differentiation, and resistance to conventional therapy are sufficient to give rise to recurrent tumors following treatment [4]. Despite continuing efforts to study BTSCs, an effective therapy that targets BTSCs has remained elusive. Immunotherapies for glioma include cytokine modulation, adoptive immunotherapy, and active immunotherapy. Recently, active immunotherapy using a peptide vaccine has shown encouraging results for high-grade glioma, and clinical trials are ongoing [510]. Moreover, the effectiveness of immunotherapy in targeting BTSCs has been demonstrated [11-13]. The latest findings related to BTSCs and immunotherapy are reviewed in this article.

\section{BRAIN TUMOR STEM CELLS}

CSCs are thought to be a subpopulation of tumor cells with the capacity for self-renewal and multilineage differentiation, resulting in the heterogeneity of cancer cells [14]. CSCs were first identified in acute myeloid leukemia in 1997 [2]. The subsequent identification of

${ }^{*}$ Address corresponding to this author at 35 Shinanomachi, Shinjuku-ku, Tokyo, 160-8582, Japan; Tel: 8135363 3808; Fax: 8133354 8053;

E-mail: todam@z2.keio.jp
CSCs in brain tumors, prostate cancer, colon cancer, breast cancer, pancreas cancer, ovary cancer and melanoma established the important role of CSC in the tumorigenesis of several cancer types.

\subsection{Identification of Brain Tumor Stem Cells}

The first identification of BTSCs in GBM was reported in 2003 [3]. BTSCs exhibit many similarities to normal neural stem cells (NSCs). The characteristics of BTSCs are the ability to generate clonally derived cells, self-renew, and the potential to differentiate into multiple lineages (neural, astrocytic, and oligodendroglial) [15]. They also express Nestin and Sox2 that are thought to be NSC markers [4]. Initially, BTSCs were cultured as spheroids in serum-free media containing the epidermal growth factor (EGF) and the fibroblastic growth factor (FGF) [4, 16]. Lee et al. reported that tumor cells maintained in NSC culture conditions could be stably preserved and form tumors similar to parental tumors in immunodeficient mice [4]. Presently, as culture methods have diversified, NSCs are cultured in vitro as spheres, or under adherent conditions in two-dimensional cultures or threedimensional matrices. Sphere-forming assays that were initially used to culture NSC are not the only procedure to establish NSCs and are considered to have limitations in evaluating NSCs when removed from their in vivo environment [17]. In addition, in CSC cultures, the sphere-forming assay is not the only assay to isolate CSCs as it is suggested to reflect the distinct behavior of cells outside of their original environment.

\subsection{Molecular Markers}

The identification and purification of BTSCs from human GBMs and medulloblastomas were first 
reported by Singh et al. and CD133 was thought to be an important BTSC marker [16]. In this report, as few as $100 \mathrm{CD} 133$ + cells were enough to form xenograft brain tumors in immunocompromised mice, and histologically, these tumors resembled the patient's tumor. In contrast, as many as $1 \times 10^{5}$ CD133- cells could not generate tumors [16]. However, other groups have reported that CD133- tumor cells isolated from GBMs have displayed stem-like cell properties [18, 19]. A more recent report suggested that CD133- cells may result in brain tumor initiation and that CD133- cells can generate a CD133+ cell population [20]. It is still unclear whether CD133 is a marker of BTSCs and whether it is associated with tumor initiation. Other stem cell markers have also been suggested [21-23]. Son et al. demonstrated that stage-specific embryonic antigen 1 (SSEA-1; CD15)-positive GBM cells fulfill the functional criteria for BTSCs [21]. In this report, SSEA$1+$ cells were highly tumorigenic in vivo and exhibited self-renewal and multilineage differentiation. Integrin $\alpha 6$ has also been reported as a BTSC marker. Lathia et al. demonstrated that targeting integrin $\alpha 6$ in BTSCs inhibited self-renewal, proliferation, and tumor formation capacity [22]. Anido et al. reported that BTSCs in GBM express high levels of CD44 and the inhibitor of DNA-binding protein 1 (Id1) [23]. Inhibition of the transforming growth factor- $\beta$ (TGF- $\beta$ ) pathway decreased the CD44/Id1 high population and prevented tumor initiation and recurrence. Still, the specific BTSC marker has not been discovered. It is important to discover a reliable BTSC marker because it would allow effective enrichment and targeting of BTSCs. Further studies about BTSC markers are ongoing (Table 1).

\subsection{Signal Transduction}

Various proteins and signaling pathways present in BTSCs have been reported [24-33]. These include transcription factors such as oligodendrocyte lineage transcription factor 2 (Olig2), Nanog, and Bmi1, receptor tyrosine kinases such as epidermal growth factor receptor (EGFR) and platelet-derived growth factor receptor (PDGFR), signaling pathways involved in neural development such as Sonic Hedgehog $(\mathrm{SHH})$, Notch, and major pathways regulating survival and proliferation. In addition, other pathways such as the TGF- $\beta$ /BMP pathway, have been reported to be associated with differentiation of BTSCs, [34-36].

Olig2 is suggested to be involved in the proliferation of neural progenitors, in addition to glioma formation. Ligon et al. showed that Olig2 can regulate the lineagerestricted pathway critical for proliferation of normal and tumorigenic neural stem cells [24].

Nanog is a transcription factor that controls the stemness of embryonic stem cells, and is expressed in several human cancers [37]. The SHH-Gli1 pathway regulates the proliferation of neural progenitor cells [38] and may have an important role in the self-renewal and tumor growth of glioma BTSCs [25-29].

Bmi1 was originally identified as an oncogene involved in the induction of lymphoma [39, 40], and has been shown to be essential for the proliferation and self-renewal of NSCs [41]. In an orthotropic transplantation model of glioma, Bmi1 was reported to be required for tumor development and regulates BTSCs [30].

The Notch pathway is important in the biology of normal NSCs as well as BTSCs [31, 42]. Elevated Notch signaling enhances the efflux of cytotoxic drugs through $A B C$ transporters such as ABCG2, thereby contributing to the resistance of BTSC to conventional therapies.

The PI3K-AKT-mTOR pathway is the major signaling pathway activated by receptor tyrosine kinases (RTK), including EGFR and PDGFR in GBM [43], and is a cell survival pathway. In GBM and medulloblastoma, this pathway results in stem-like behavior [32]. Furthermore, activation of this signaling

Table 1: Brain Tumor Stem Cell Markers

\begin{tabular}{|c|c|c|}
\hline BTSC marker & BT type & Reference \\
\hline \hline CD133 & GBM, MB & {$[16]$} \\
\hline SSEA-1 & GBM & {$[21]$} \\
\hline Integrin $\alpha 6$ & GBM & {$[22]$} \\
\hline CD44/ld1 & GBM & {$[23]$} \\
\hline
\end{tabular}

BTSC, brain tumor stem cell; BT, brain tumor; SSEA-1, stage-specific embryonic antigen 1; Id1, inhibitor of DNA-binding protein 1; GBM, Glioblastoma; MB, Medulloblastoma. 
through PTEN loss leads to the proliferation of BTSCs [33].

TGF- $\beta$ and their family members, including bone morphogenetic proteins (BMPs), have been demonstrated to play important roles in maintenance and differentiation of normal stem cells. TGF- $\beta$ pathway was reported to be essential for BTSCs in glioma to retain their stemness and inhibition of TGF- $\beta$ signaling may lead to differentiation of BTSCs [34]. BMP-4 has been shown to induce astrocytic differentiation and reduce tumorigenicity of BTSCs in glioma [35]. Lee et al. identified BMP type 1B receptor (BMPR1B) that induces GBM BTSCs to differentiate [36].

\subsection{The BTSC Niche}

Like NSCs, BTSCs are thought to require the specific microenvironment, termed "niche", for survival and self-renewal. BTSCs residing in the niche sustain tumor survival by being protected from external factors, and maintain their stemness by receiving some factors from within the niche. The important factors associated with the BTSC niche are thought to be angiogenesis and oxygen nutrition. It has been shown that BTSCs exist in a vascular niche and that coculture of BTSCs with endothelial cells enhanced tumor growth [44]. BTSCs themselves secrete vascular endothelial growth factor (VEGF) and promote angiogenesis [45]. In addition, 2 different reports suggest that BTSCs could transdifferentiate into endothelial cells directly [46, 47]. A hypoxic environment as part of the NSC niche is important for maintaining their self-renewal [48]. Hypoxia induced factor (HIF) is a transcription factor that functions as a master regulator of oxygen homeostasis, and depletion of HIFs in BTSCs is reported to inhibit their self-renewal, survival, and tumor initiation [49, 50]. HIFs also play an important role in upregulating VEGF signaling and promoting angiogenesis, resulting in maintenance of the tumor and its microenvironment.

\subsection{Controversies of CSCs}

Despite several efforts to characterize BTSCs, some inconsistent findings have been noted, as mentioned above. These contradictory results suggest that in contrast to normal NCSs, BTSCs may be heterogeneous. Moreover, the diversity of BTSCs might be a cause of GBM heterogeneity. BTSCs may not be a static population, but instead a dynamically modulated population due to its genomic instability, differentiation, and plasticity. Piccirillo et al. reported the existence of distinct BTSCs in the same GBM [51]. The plasticity of CSCs was reported previously with respect to melanoma [52]; therefore, a similar theory may be true in the case of BTSCs.

Although CSCs were defined as cells that can initiate tumors in vivo, the current definition does not require the ability to form tumors upon implantation [53]. It was shown that tumor cells with a low expression of Id1, a stem cell marker, and those that were unable to form spheres, had a higher tumorigenicity in high-grade glioma [54]. Thus, the definition of CSCs is now being re-evaluated. Visvader pointed out the difference between tumor-initiating cells and CSCs [55]. The former corresponds to cells of origin that acquire the first cancer-promoting mutations, whereas the latter relates to tumor-propagating cells.

In summary, many unanswered questions regarding the characterization of BTSCs, including their markers, niche, and other defining factors, still remain. Further studies are necessary to improve our understanding.

\section{GLIOMA AND IMMUNOTHERAPY}

Currently, many clinical trials of immunotherapy for malignant gliomas are ongoing. We describe the basic concept of immunotherapy and then review recent studies on immunotherapy for GBMs and BTSCs.

\subsection{Basic Immunology}

The immune system has an important role in preventing foreign and dangerous antigens from damaging the body. Innate immunity involves an antigen-nonspecific response, while adaptive immunity is based on the antigen-specific response [56, 57]. B cells mediate antibody immunity and killer $\mathrm{T}$ cells play a main role in the cellular immune response. Helper $T$ cells are involved in both forms of adaptive immunity. B cells recognize specific extracellular antigens and secrete antigen-specific antibodies. Cytotoxic $T$ lymphocytes (CTLs) bind antigens presented by antigen presenting cells (APCs), including DCs and macrophages. In the presence of helper $T$ cells and cytokines, including interleukin 2 (IL2), IFN $\gamma, \mathrm{GM}-\mathrm{CSF}$, and IL12, CTLs switch to the effector phase and destroy cells expressing a specific antigen [57]. Antigens are presented to $\mathrm{T}$ cells in the context of the major histocompatibility complex (MHC) class 1 associated with CD8+ CTLs and MHC class 2 with CD4+ helper T cells. 


\subsection{Immune Response in the Central Nervous System}

Traditionally, the central nervous system (CNS) has been considered an immunologically privileged site [58], due to its separation from antibodies and lymphocytes by the blood brain barrier (BBB), the lack of a lymphatic system, the paucity of APCs [59], and the low expression level of MHC [60]. However, recent reports revised these considerations and revealed that the BBB is not an absolute barrier to lymphocyte tracking [61, 62]. Microglias are resident major APCs in the central nervous system, and play an important role in immune responses in the brain [63]. Goldmann et al. showed that the cerebrospinal fluid connects to the cervical lymph nodes, where naïve T cells can access it in a murine model [61]. Furthermore, it became clear that activated CTLs can pass through the BBB [62]. Taken together, these findings suggest that the CNS is not an immunologically privileged site in the strict sense, but rather an immunologically distinct organ.

\subsection{Mechanism of Glioma Cell Immunoresistance}

Glioma immunotherapy primes the patient's own immune system to attack glioma cells and seems to be a promising new therapy. However, clinical trials of glioma immunotherapy have yet to yield a satisfactory outcome. One reason is that GBM cells may use the mechanism of immunosuppression. GBM cells and BTSCs secrete immunosuppressive factors, and this leads to the degradation of cellular immunity and to abnormal immune cell activation [64]. These cells prevent mature DCs from functioning as APCs through the secretion of immunosuppressive cytokines, including TGF- $\beta \beta$, prostaglandin E2 (PGE2), VEGF, IL6, and IL-10 $[65,66]$. TGF- $\beta \beta$ is known to expand the pool of immunosuppressive regulatory $T$ cells, resulting in the suppression of T-cell proliferation [67]. PGE2 downregulate $\mathrm{MHC}$ class 2 expression and antigen processing [64]. VEGF, IL6, and IL12 activate signal transducer and activator of transcription 3 (STAT3), which has been shown to inhibit macrophage activation, induce immunosuppressive macrophage phenotype (M2), and promote GBM tumorigenesis [6870]. Blockage of STAT3 signaling has been reported to inhibit T-cell apoptosis and reduce the BTSC-induced regulatory T cells pool [67]. BTSCs express MHC class 1 and $\mathrm{B} 7-\mathrm{H} 1$ [67]. The decreased expression of $\mathrm{B} 7$ protein prevents $\mathrm{T}$-cell proliferation, and the increased expression of $\mathrm{B} 7-\mathrm{H} 1$ and ligand for apoptosis stimulating fragment (FasL) induces T-cell anergy and apoptosis. Thus, BTSCs have been shown to maintain the immunosuppressive environment called the immune niche [71].

\subsection{Current Immunotherapy in Glioma}

Various strategies of immunotherapy targeting GBM have been developed, such as cytokine therapy, adoptive immunotherapy, and active immunotherapy (Table 2).

\subsubsection{Cytokine Modulation}

Cytokine modulation is a therapeutic method targeted at tumor-induced immune suppression. Moreover, in other tumors such as those of renal cancer, metastatic melanoma, and non-Hodgkin lymphoma, IL2 treatment has had positive results [7274]. Clinical trials using cytokine modulation, including TGF- $\beta \beta$, IL2, IL12, and interferons (INF- $\alpha \alpha$, INF- $\beta \beta$, and IFN- $\gamma \gamma$ ), have been performed for gliomas. However, the results of these clinical trials were generally disappointing [75-80]. In contrast, among these studies, the blockage of TGF- $\beta \beta$ showed promising results in a phase IIB clinical trial [81].

Table 2: Current Immunotherapy for Malignant Gliomas

\begin{tabular}{|c|c|c|c|}
\hline \multicolumn{2}{|c|}{ Strategy for immunotherapy } & Advantages & Disadvantages \\
\hline \hline Cytokine therapy & CTLs & $\begin{array}{c}\text { Relative ease of preparation } \\
\text { and maintenance } \\
\text { Uniform quality }\end{array}$ & $\begin{array}{c}\text { Low tumor-specific cytotoxity } \\
\text { Adoptive immunotherapy }\end{array}$ \\
\hline Active immunotherapy (vaccine therapy) & ATCs & $\begin{array}{c}\text { Adoptable for a broad range of } \\
\text { tumor antigens }\end{array}$ & $\begin{array}{c}\text { Difficulty of preparation and } \\
\text { maintenance }\end{array}$ \\
\hline & Peptides & $\begin{array}{c}\text { Relative ease of preparation } \\
\text { and maintenance } \\
\text { Uniform quality }\end{array}$ & HLA restriction \\
Restrictions of tumor antigens \\
\hline
\end{tabular}

CTL, cytotoxic T lymphocyte; ATC, autologous tumor cell. 
Trabedersen, a TGF- $\beta \beta 2$ antisense oligonucleotide, is currently in the phase III stage of clinical trials for anaplastic astrocytomas [82].

\subsubsection{Adoptive Immunotherapy}

Adoptive immunotherapy refers to cell transfer therapy. The patient's immune cells are matured $e x$ vivo to generate activity specific for glioma cell antigens and are subsequently reinfused into the patient. The activated cells are injected into the tumor cavity or administered systemically. The first type of immune cells used in this therapy were lymphocyte-activated killer cells (LAK cells), which are autologous peripheral blood lymphocytes stimulated with IL2 in vitro. While the result of infusing LAK cells directly into the tumor cavity was rather encouraging [83], these cells failed to effectively migrate to the brain because of the BBB [84]. CTLs are also used for adoptive immunotherapy. CTLs are generated ex vivo by stimulation of peripheral blood mononuclear cells (PBMCs), which have a specific activation for tumor antigens. Activated $T$ cells can migrate to the brain via the BBB and selectively affect tumor cells. Adoptive therapy combined with other strategies of immunotherapy has shown to be promising. Genetically, modified T cells that express a chimerical antigen receptor for tumor antigens, such as IL-13, Receptor $\alpha 2$ (IL-13R $\alpha 2$ ), and HER2 have been reported to induce GBM regression in animal models $[85,86]$.

\subsubsection{Active Immunotherapy}

Active immunotherapy is otherwise known as vaccine therapy. Vaccines are derived from autologous tumor cells, tumor cell lysates, or specific peptides that encode tumor antigens. Identification of a large number of tumor associated antigens (TAAs) has advanced cancer vaccines, as in 1991, it became technically possible to amplify TAAs by cDNA cloning of these TAAs [87]. An injection of TAAs stimulates APCs to present tumor antigens to the patient's immune system. Then, lymphocytes sensitized against tumor antigens migrate to the tumor and attack the tumor cells [88]. Vaccines seem to be promising in inducing an antiglioma immune response without major side effects. Some of the approaches for active immunotherapy involve using peptides, DCs, autologous tumor cells, and heat shock proteins (HSPs). Peptide vaccines are discussed in detail later.

DCs are the main APCs that activate an immune response. DCs pulsed with tumor antigens are injected into patients as vaccine. Many animal and clinical studies have been conducted using DC-based vaccination. The most recent results of phase $\mathrm{I} / \mathrm{II}$ trial for 77 patients with newly diagnosed GBM confirmed that the treatment was feasible without major toxicity and the median overall survival was 18.3 months [89].

Vaccines using autologous tumor cells, cultured and modified from the resected original tumors, activate the immune system with an increased number of potential glioma antigens when they are injected back into the patients. Recent clinical trials for GBM support the safety of this method, although the results are controversial. One report could not show any significant effect [90], while another demonstrated a prolonged median survival [91]. In a pilot study using autologous formalin-fixed tumor vaccines, performed by Ishikawa et al. the safety was confirmed and vaccine therapy improved the outcome of GBM [92]. Further clinical investigations are continuing.

HSPs, instead of DCs, are used to deliver tumor antigens. HSPs are chaperone proteins that aid in the folding of many proteins within the cell. Specific HSPs that have been isolated from the excised tumors and purified, are used as vaccines [93]. In addition, HSPs are potent immune activators. A favorable outcome has been reported [94], and clinical trials using an HSP vaccine for GBM are in progress.

\subsection{Peptide-Based Vaccines}

Peptide-based vaccines are the most promising immunotherapy technique, and now, there are several ongoing clinical studies. The peptides used as cancer vaccines consist of 9 amino acids capable of binding to a particular MHC class 1 antigen with the ability to activate CTLs reactive to tumor cells. Peptide antigens are ingested and processed by APCs. Then, APCs present these peptide antigens in association with MHC class 1 molecules on their surface. Peptide antigen/MHC class 1 complexes stimulate CD8+ T cells to make antigen-specific CTLs. These activated CTLs travel from the lymph nodes into the blood circulation and finally migrate to the brain where they eliminate glioma cells (Figure 1). Although several clinical trials of peptide-based vaccines for various cancers have been reported, the responses were not significant [95]. In contrast, some recent clinical trials of peptide-based vaccines for malignant gliomas have obtained promising results.

\subsubsection{EGFRvIII}

The epidermal growth factor receptor vIII (EGFRvIII) is a mutated form of the wild-type EGFR. It is not 


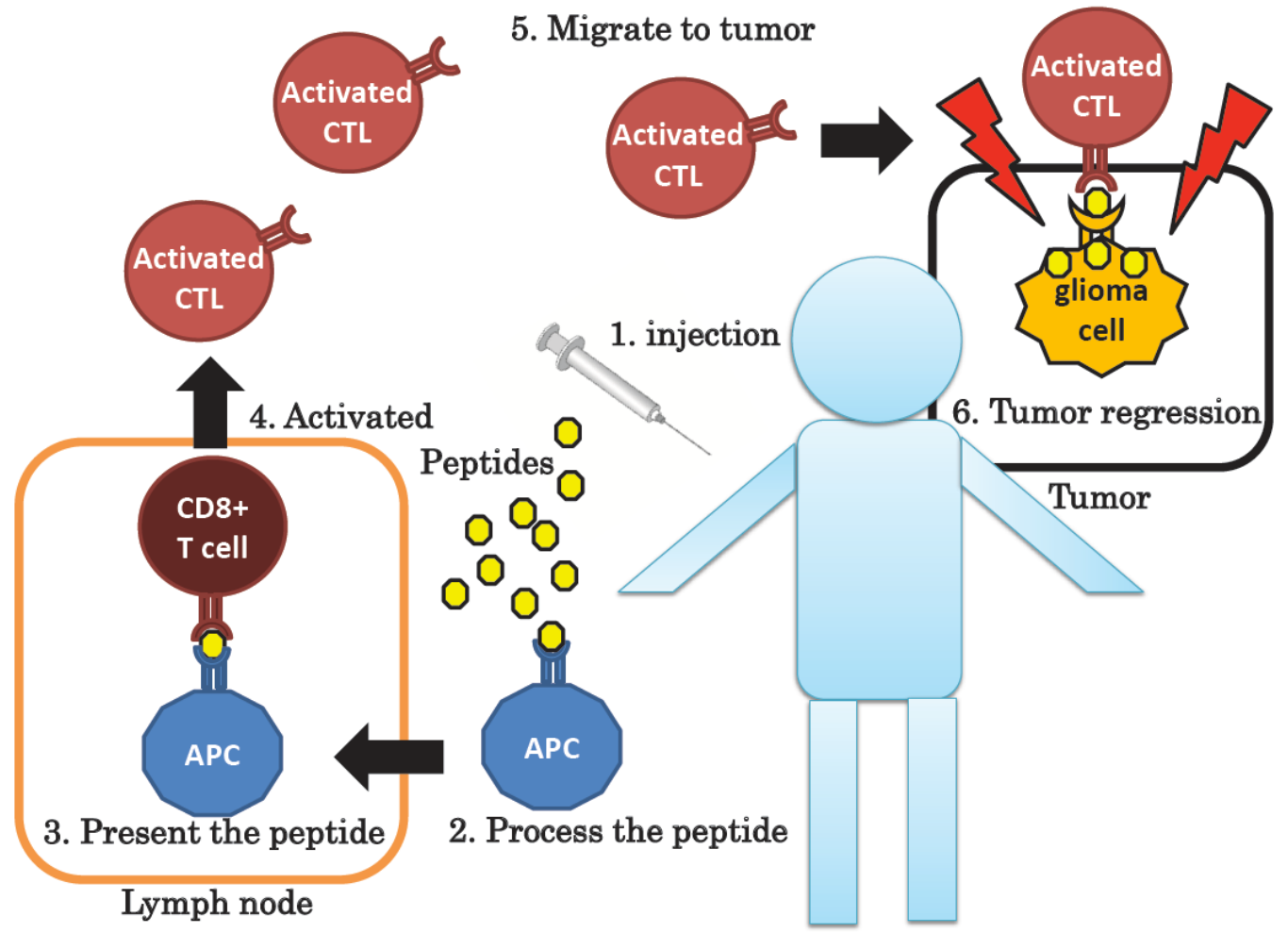

Figure 1: Peptide vaccine strategy.

Intradermal injection of peptide vaccine is repeated. Antigen-presenting cells (APCs) process the peptide antigen and then present it in association with antigen/major histocompatibility complex (MHC) class 1 molecules on the surface of APCs. Peptide antigen/MHC class 1 complexes stimulate CD8+ T cells to make antigen-specific cytotoxic T cells (CTLs) in the lymph node. Activated antigen-specific CTLs migrate to the brain and destroy glioma cells, leading to tumor regression.

expressed in the normal brain, but is overexpressed in malignant glioma and has a prevalence of $20-30 \%$ in GBMs [96, 97]. In contrast to earlier vaccine trials targeting EGFRvIII, which yielded unimpressive results, current trials using a novel EGFRvIII epitope have produced encouraging data [5, 98]. An EGFRvilltargeted peptide vaccine began a phase I clinical trial, the Vaccine for Intra-Cranial Tumors I (VICTORI), and continued to the phase II study, A Complementary Trial of an Immunotherapy Against Tumor Specific EGFRvIII (ACTIVATE) [99]. In the VICTORI phase I trial, 20 patients with malignant glioma (WHO grade $3 / 4$ ) were enrolled and 16 of these patients were administered vaccines after surgery and radiotherapy. Autologous DCs were pulsed with $500 \mu \mathrm{g}$ of an EGFRvIll Peptide (PEPVIII, LEEKKGNYVVTDHC) conjugated to the adjuvant molecule keyhole limpet hemocyanin (KLH). All patients were vaccinated 3 times via an intradermal injection. The median time to progression was 11.7 months and the median survival of GBM patients treated with the vaccines was 22.8 months; both of these time periods are longer than those of patients treated with temozolomide, whose results are 6.3 months and 14.6 months, respectively [100].
ACTIVATE, the following phase II trial, evaluated the efficiency of PEPvIII-KLH and GM-CSF without the use of DCs [5]. Patients with newly diagnosed GBM were enrolled into this trial and vaccinated monthly until there was evidence of tumor progression. The median time to progression was 14.2 months and the median survival was 32 months, both of which are longer than the unvaccinated control group. In addition, $100 \%$ of recurrent tumors lost the expression of EGFRvIII. This suggests that the vaccine therapy was immunologically effective with successful elimination of EGFRvIllpositive tumor cells. The follow-up phase II multicenter trial enrolled 21 patients with EGFRvIII-positive GBMs who were treated monthly with PEPvIII-KLH, following the standard surgical, radio-, and temozolomide therapy, until tumor progression was observed. The median time to progression was 16.6 months [6]. The EGFRvIll-targeted vaccine (CDX-10) is in an ongoing phase III randomized clinical trial and awaiting results.

\subsubsection{Personalized Peptide Vaccine}

In personalized peptide vaccines, patients who had exhibited a preexisting response to specific peptides were vaccinated with these peptides. By utilizing this 
strategy, a faster and stronger activation of CTLs can be induced [101]. The results of a phase I study of personalized peptide vaccination for malignant glioma have been reported [7]. The study enrolled 25 malignant glioma patients. Prevaccination PBMCs and plasma were collected to examine the response to peptides in HLA-A24+ or HLA-A2+ patients. The most frequently reactive peptides were derived from squamous cell carcinoma antigen recognized by $T$ cells 3 (SART3), lymphocyte-specific protein tyrosine kinase, and multidrug resistance-associated protein 3 (MRP3) antigens. The clinical response induced 5 partial responses (PR) and the median survival was 18 months. A recent clinical study of personalized peptide vaccines for HLA-A24+ patients with GBM also reported promising results [8]

\subsubsection{WT1}

The WT1 gene was isolated as a gene responsible for Wilms tumor, and it is involved in cell proliferation and apoptosis [102]. As the WT1 gene was frequently overexpressed in various tumors including gliomas, the WT1 protein was an attractive target for immunotherapy. A phase II clinical trial for a WT1 peptide vaccination for GBM was reported in 2008 [9]. Twenty-one patients with recurrent GBM were enrolled, and the HLA-A2402-restricted modified 9-mer WT1 peptide was used. The clinical response induced 2 PRs and the median progression-free survival was 5 months. Several clinical studies are now ongoing.

\subsubsection{IL-13 Receptor $\alpha 2$}

IL-13R $\alpha 2$ is a cell-surface receptor highly expressed on glioma cells, but not at significant levels in normal brain tissue. Therefore, the IL-13R $\alpha 2$ antigen is thought to be a good target for immunotherapy [103]. IL-13R $\alpha 2$ vaccine has been demonstrated to induce strong immunological antitumor effects in a mouse glioma model [104, 105]. Iwami et al. conducted a phase I trial of $D C$ vaccination in patients with recurrent malignant glioma using $2 \mathrm{IL}-13 \mathrm{R} \alpha 2$-derived peptides restricted to HLA-A*0201 and HLA-A*2402 [10]. Eight patients were enrolled, 1 achieved stable disease for 16 months and another had 1 lesion that dramatically regressed for 4 months.

\section{TARGETING BTSCS USING IMMUNOTHERAPY}

BTSCs are resistant to conventional therapies including chemotherapy and radiotherapy due to the expression of several ABC transporters, an active DNA-repair capacity, and resistance to apoptosis [33,
106]. In addition, BTSCs create their own immune niche, which contributes to the mechanism of immune privilege as described above. Thus, BTSCs and their immune niche are potential therapeutic targets. Several recent studies reported immunotherapy that targeted BTSCs [11-13]. Pellegatta et al. found that DC immunotherapy could target murine glioma stem-like cells-GL261 neurospheres [11]. In this study, DC loaded with GL261 neurospheres eliminated $60 \%$ of GL261 neurosphere tumors, whereas DC loaded with GL261-adherent cells had no effect on theGL261 neurosphere tumors. Similar results pertaining to GBM neurosphere-targeting immunotherapy have been reported elsewhere [12]. Xu et al. demonstrated that an antigen-specific response could be generated from DC vaccination using rat glioma stem-like cell-associated antigens. SOX2 was regarded as the stem cell associated-antigen as it is highly expressed on glioma stem-like cells. Specific CTLs were raised against HLAA0201-restricted SOX2-derived peptides that were capable of lysing glioma cells [107]. Ueda et al. demonstrated that vaccination with SOX6 DNA induced CTLs specific for glioma in mice [108]. In vitro stimulation with $\mathrm{HLA}-\mathrm{A}^{*} 0201$ (A2)- and HLA-A*2402 (A24)-restricted SOX6 peptides resulted in the induction of peptide-specific CTLs in PBMCs derived from glioma patients. These CTLs were able to lyse the majority of glioma cell lines and BTSC lines derived from human GBM [13]. These results suggest that vaccine immunotherapy may have the potential to deplete human BTSCs.

\section{CONCLUSION}

Although not yet fully characterized, BTSCs are increasingly being recognized as a main cause of resistance to treatment in malignant brain tumors, especially GBM. Consequently, it is imperative that these cells are targeted using novel and specific therapies. Recent advances in immunotherapy mean that it is possible to target BTSCs and to tailor the therapy to the characteristics of individual patients. Immunotherapy can be considered a promising new treatment modality, which, perhaps in combination with surgery and chemotherapy, might prolong survival for patients with GBM.

\section{REFERENCES}

[1] Stupp R, Hegi ME, Mason WP, et al. Effects of radiotherapy with concomitant and adjuvant temozolomide versus radiotherapy alone on survival in glioblastoma in a randomised phase III study: 5-year analysis of the EORTCNCIC trial. Lancet Oncol 2009; 10(5): 459-66. http://dx.doi.org/10.1016/S1470-2045(09)70025-7 
[2] Bonnet D, Dick JE. Human acute myeloid leukemia is organized as a hierarchy that originates from a primitive hematopoietic cell. Nat Med 1997; 3(7): 730-7. http://dx.doi.org/10.1038/nm0797-730

[3] Singh SK, Clarke ID, Terasaki M, et al. Identification of a cancer stem cell in human brain tumors. Cancer Res 2003; 63(18): 5821-8.

[4] Lee J, Kotliarova S, Kotliarov $Y$, et al. Tumor stem cells derived from glioblastomas cultured in bFGF and EGF more closely mirror the phenotype and genotype of primary tumors than do serum-cultured cell lines. Cancer Cell 2006; 9(5): 391-403.

http://dx.doi.org/10.1016/j.ccr.2006.03.030

[5] Heimberger AB, Crotty LE, Archer GE, et al. Epidermal growth factor receptor VIII peptide vaccination is efficacious against established intracerebral tumors. Clin Cancer Res 2003; 9(11): 4247-54.

[6] Sampson JH, Heimberger AB, Archer GE, et al. Immunologic escape after prolonged progression-free survival with epidermal growth factor receptor variant III peptide vaccination in patients with newly diagnosed glioblastoma. J Clin Oncol 2010; 28(31): 4722-9.

http://dx.doi.org/10.1200/JCO.2010.28.6963

[7] Yajima N, Yamanaka R, Mine $T$, et al. Immunologic evaluation of personalized peptide vaccination for patients with advanced malignant glioma. Clin Cancer Res 2005; 11(16): 5900-11.

http://dx.doi.org/10.1158/1078-0432.CCR-05-0559

[8] Terasaki M, Shibui S, Narita $Y$, et al. Phase I trial of a personalized peptide vaccine for patients positive for human leukocyte antigen--A24 with recurrent or progressive glioblastoma multiforme. J Clin Oncol 2011; 29(3): 337-44. http://dx.doi.org/10.1200/JCO.2010.29.7499

[9] Izumoto S, Tsuboi A, Oka Y, et al. Phase II clinical trial of Wilms tumor 1 peptide vaccination for patients with recurrent glioblastoma multiforme. J Neurosurg 2008; 108(5): 963-71. http://dx.doi.org/10.3171/JNS/2008/108/5/0963

[10] Iwami K, Shimato S, Ohno M, et al. Peptide-pulsed dendritic cell vaccination targeting interleukin- 13 receptor alpha2 chain in recurrent malignant glioma patients with $H L A-A^{*} 24 / A^{*} 02$ allele. Cytotherapy 2012. http://dx.doi.org/10.3109/14653249.2012.666633

[11] Pellegatta S, Poliani PL, Corno D, et al. Neurospheres enriched in cancer stem-like cells are highly effective in eliciting a dendritic cell-mediated immune response against malignant gliomas. Cancer Res 2006; 66(21): 10247-52. http://dx.doi.org/10.1158/0008-5472.CAN-06-2048

[12] Xu Q, Liu G, Yuan X, et al. Antigen-specific T-cell response from dendritic cell vaccination using cancer stem-like cellassociated antigens. Stem Cells 2009; 27(8): 1734-40. http://dx.doi.org/10.1002/stem.102

[13] Ueda R, Ohkusu-Tsukada K, Fusaki N, et al. Identification of HLA-A2- and A24-restricted T-cell epitopes derived from SOX6 expressed in glioma stem cells for immunotherapy. Int J Cancer 2010; 126(4): 919-29.

[14] Clarke MF, Dick JE, Dirks PB, et al. Cancer stem cells-perspectives on current status and future directions: AACR Workshop on cancer stem cells. Cancer Res 2006; 66(19): 9339-44.

http://dx.doi.org/10.1158/0008-5472.CAN-06-3126

[15] Vescovi AL, Galli R, Reynolds BA. Brain tumour stem cells. Nat Rev Cancer 2006; 6(6): 425-36. http://dx.doi.org/10.1038/nrc1889

[16] Singh SK, Hawkins C, Clarke ID, et al. Identification of human brain tumour initiating cells. Nature 2004; 432(7015): 396-401.

http://dx.doi.org/10.1038/nature03128
[17] Pastrana E, Silva-Vargas V, Doetsch F. Eyes wide open: a critical review of sphere-formation as an assay for stem cells. Cell Stem Cell 2011; 8(5): 486-98. http://dx.doi.org/10.1016/j.stem.2011.04.007

[18] Beier D, Hau P, Proescholdt M, et al. CD133(+) and CD133(-) glioblastoma-derived cancer stem cells show differential growth characteristics and molecular profiles. Cancer Res 2007; 67(9): 4010-5. http://dx.doi.org/10.1158/0008-5472.CAN-06-4180

[19] Joo KM, Kim SY, Jin X, et al. Clinical and biological implications of CD133-positive and CD133-negative cells in glioblastomas. Lab Invest 2008; 88(8): 808-15. http://dx.doi.org/10.1038/labinvest.2008.57

[20] Chen R, Nishimura MC, Bumbaca SM, et al. A hierarchy of self-renewing tumor-initiating cell types in glioblastoma. Cancer Cell 2010; 17(4): 362-75.

http://dx.doi.org/10.1016/j.ccr.2009.12.049

[21] Son MJ, Woolard K, Nam DH, Lee J, Fine HA. SSEA-1 is an enrichment marker for tumor-initiating cells in human glioblastoma. Cell Stem Cell 2009; 4(5): 440-52. http://dx.doi.org/10.1016/i.stem.2009.03.003

[22] Lathia JD, Gallagher J, Heddleston JM, et al. Integrin alpha 6 regulates glioblastoma stem cells. Cell Stem Cell 2010; 6(5): 421-32.

http://dx.doi.org/10.1016/j.stem.2010.02.018

[23] Anido J, Saez-Borderias A, Gonzalez-Junca A, et al. TGFbeta Receptor Inhibitors Target the CD44(high)/ld1(high) Glioma-Initiating Cell Population in Human Glioblastoma. Cancer Cell 2010; 18(6): 655-68. http://dx.doi.org/10.1016/..ccr.2010.10.023

[24] Ligon KL, Huillard E, Mehta S, et al. Olig2-regulated lineagerestricted pathway controls replication competence in neural stem cells and malignant glioma. Neuron 2007; 53(4): 50317

http://dx.doi.org/10.1016/i.neuron.2007.01.009

[25] Clement V, Sanchez P, de Tribolet N, Radovanovic I, Ruiz Altaba A. HEDGEHOG-GLI1 signaling regulates human glioma growth, cancer stem cell self-renewal, and tumorigenicity. Curr Biol 2007; 17(2): 165-72. http://dx.doi.org/10.1016/i.cub.2006.11.033

[26] Dahmane N, Sanchez P, Gitton $Y$, et al. The Sonic Hedgehog-Gli pathway regulates dorsal brain growth and tumorigenesis. Development 2001; 128(24): 5201-12.

[27] Ruiz i Altaba A, Stecca B, Sanchez P. Hedgehog--Gli signaling in brain tumors: stem cells and paradevelopmenta programs in cancer. Cancer Lett 2004; 204(2): 145-57. http://dx.doi.org/10.1016/S0304-3835(03)00451-8

[28] Zbinden $M$, Duquet A, Lorente-Trigos A, Ngwabyt SN Borges I, Ruiz i Altaba A. NANOG regulates glioma stem cells and is essential in vivo acting in a cross-functional network with GLI1 and p53. EMBO J 2010; 29(15): 2659-74. http://dx.doi.org/10.1038/emboj.2010.137

[29] Po A, Ferretti E, Miele E, et al. Hedgehog controls neural stem cells through p53-independent regulation of Nanog. EMBO J 2010; 29(15): 2646-58.

http://dx.doi.org/10.1038/emboj.2010.131

[30] Bruggeman SW, Hulsman D, Tanger E, et al. Bmi1 controls tumor development in an Ink4a/Arf-independent manner in a mouse model for glioma. Cancer Cell 2007; 12(4): 328-41. http://dx.doi.org/10.1016/j.ccr.2007.08.032

[31] Fan X, Matsui W, Khaki L, et al. Notch pathway inhibition depletes stem-like cells and blocks engraftment in embryonal brain tumors. Cancer Res 2006; 66(15): 7445-52. http://dx.doi.org/10.1158/0008-5472.CAN-06-0858

[32] Hambardzumyan D, Becher OJ, Rosenblum MK, Pandolf PP, Manova-Todorova K, Holland EC. PI3K pathway regulates survival of cancer stem cells residing in the 
perivascular niche following radiation in medulloblastoma in vivo. Genes Dev 2008; 22(4): 436-48.

http://dx.doi.org/10.1101/gad.1627008

[33] Bleau AM, Hambardzumyan D, Ozawa $T$, et al. PTEN/PI3K/Akt pathway regulates the side population phenotype and ABCG2 activity in glioma tumor stem-like cells. Cell Stem Cell 2009; 4(3): 226-35.

http://dx.doi.org/10.1016/.stem.2009.01.007

[34] Ikushima H, Todo T, Ino Y, Takahashi M, Miyazawa K, Miyazono K. Autocrine TGF-beta signaling maintains tumorigenicity of glioma-initiating cells through Sry-related HMG-box factors. Cell Stem Cell 2009; 5(5): 504-14. http://dx.doi.org/10.1016/.stem.2009.08.018

[35] Piccirillo SG, Reynolds BA, Zanetti N, et al. Bone morphogenetic proteins inhibit the tumorigenic potential of human brain tumour-initiating cells. Nature 2006; 444(7120): 761-5. http://dx.doi.org/10.1038/nature05349

[36] Lee J, Son MJ, Woolard K, et al. Epigenetic-mediated dysfunction of the bone morphogenetic protein pathway inhibits differentiation of glioblastoma-initiating cells. Cancer Cell 2008; 13(1): 69-80.

http://dx.doi.org/10.1016/j.ccr.2007.12.005

[37] Chambers I, Colby D, Robertson $M$, et al. Functional expression cloning of Nanog, a pluripotency sustaining factor in embryonic stem cells. Cell 2003; 113(5): 643-55. http://dx.doi.org/10.1016/S0092-8674(03)00392-1

[38] Palma V, Lim DA, Dahmane N, et al. Sonic hedgehog controls stem cell behavior in the postnatal and adult brain. Development 2005; 132(2): 335-44. http://dx.doi.org/10.1242/dev.01567

[39] Haupt Y, Alexander WS, Barri G, Klinken SP, Adams JM. Novel zinc finger gene implicated as myc collaborator by retrovirally accelerated lymphomagenesis in $\mathrm{E}$ mu-myc transgenic mice. Cell 1991; 65(5): 753-63.

http://dx.doi.org/10.1016/0092-8674(91)90383-A

[40] van Lohuizen M, Verbeek S, Scheijen B, Wientjens E, van der Gulden $H$, Berns A. Identification of cooperating oncogenes in $\mathrm{E}$ mu-myc transgenic mice by provirus tagging. Cell 1991; 65(5): 737-52.

http://dx.doi.org/10.1016/0092-8674(91)90382-9

[41] Zencak D, Lingbeek M, Kostic C, et al. Bmi1 loss produces an increase in astroglial cells and a decrease in neural stem cell population and proliferation. J Neurosci 2005; 25(24): 5774-83.

http://dx.doi.org/10.1523/JNEUROSCI.3452-04.2005

[42] Androutsellis-Theotokis A, Leker RR, Soldner F, et al. Notch signalling regulates stem cell numbers in vitro and in vivo. Nature 2006; 442(7104): 823-6.

http://dx.doi.org/10.1038/nature04940

[43] Hu X, Pandolfi PP, Li Y, Koutcher JA, Rosenblum M, Holland EC. mTOR promotes survival and astrocytic characteristics induced by Pten/AKT signaling in glioblastoma. Neoplasia 2005; 7(4): 356-68.

http://dx.doi.org/10.1593/neo.04595

[44] Calabrese $\mathrm{C}$, Poppleton $\mathrm{H}$, Kocak $\mathrm{M}$, et al. A perivascular niche for brain tumor stem cells. Cancer Cell 2007; 11(1): 6982.

http://dx.doi.org/10.1016/j.ccr.2006.11.020

[45] Bao S, Wu Q, Sathornsumetee S, et al. Stem cell-like glioma cells promote tumor angiogenesis through vascular endothelial growth factor. Cancer Res 2006; 66(16): 7843-8. http://dx.doi.org/10.1158/0008-5472.CAN-06-1010

[46] Ricci-Vitiani L, Pallini $\mathrm{R}$, Biffoni $\mathrm{M}$, et al. Tumour vascularization via endothelial differentiation of glioblastoma stem-like cells. Nature 2010; 468(7325): 824-8.

http://dx.doi.org/10.1038/nature09557
[47] Wang R, Chadalavada K, Wilshire J, et al. Glioblastoma stem-like cells give rise to tumour endothelium. Nature 2010; 468(7325): 829-33. http://dx.doi.org/10.1038/nature09624

[48] Clarke L, van der Kooy D. Low oxygen enhances primitive and definitive neural stem cell colony formation by inhibiting distinct cell death pathways. Stem Cells 2009; 27(8): 187986

http://dx.doi.org/10.1002/stem.96

[49] Heddleston JM, Li Z, McLendon RE, Hjelmeland AB, Rich $\mathrm{JN}$. The hypoxic microenvironment maintains glioblastoma stem cells and promotes reprogramming towards a cancer stem cell phenotype. Cell Cycle 2009; 8(20): 3274-84. http://dx.doi.org/10.4161/cc.8.20.9701

[50] Li Z, Bao S, Wu Q, et al. Hypoxia-inducible factors regulate tumorigenic capacity of glioma stem cells. Cancer Cell 2009; 15(6): 501-13. http://dx.doi.org/10.1016/i.ccr.2009.03.018

[51] Piccirillo SG, Combi R, Cajola L, et al. Distinct pools of cancer stem-like cells coexist within human glioblastomas and display different tumorigenicity and independent genomic evolution. Oncogene 2009; 28(15): 1807-11. http://dx.doi.org/10.1038/onc.2009.27

[52] Roesch A, Fukunaga-Kalabis M, Schmidt EC, et al. A temporarily distinct subpopulation of slow-cycling melanoma cells is required for continuous tumor growth. Cell 2010; 141(4): 583-94 http://dx.doi.org/10.1016/j.cell.2010.04.020

[53] Jordan CT. Cancer stem cells: controversial or just misunderstood? Cell Stem Cell 2009; 4(3): 203-5. http://dx.doi.org/10.1016/j.stem.2009.02.003

[54] Barrett LE, Granot Z, Coker C, et al. Self-renewal does not predict tumor growth potential in mouse models of highgrade glioma. Cancer Cell 2012; 21(1): 11-24. http://dx.doi.org/10.1016/i.ccr.2011.11.025

[55] Visvader JE. Cells of origin in cancer. Nature 2011; 469(7330): 314-22 http://dx.doi.org/10.1038/nature09781

[56] Medzhitov R, Janeway C, Jr. Innate immunity. N Engl J Med 2000; 343(5): 338-44. http://dx.doi.org/10.1056/NEJM200008033430506

[57] Abbas AK, Janeway CA, Jr. Immunology: improving on nature in the twenty-first century. Cell 2000; 100(1): 129-38. http://dx.doi.org/10.1016/S0092-8674(00)81689-X

[58] Pachter JS, de Vries HE, Fabry Z. The blood-brain barrier and its role in immune privilege in the central nervous system. J Neuropathol Exp Neurol 2003; 62(6): 593-604.

[59] Fabry Z, Raine CS, Hart MN. Nervous tissue as an immune compartment: the dialect of the immune response in the CNS. Immunol Today 1994; 15(5): 218-24. http://dx.doi.org/10.1016/0167-5699(94)90247-X

[60] Lampson LA, Hickey WF. Monoclonal antibody analysis of MHC expression in human brain biopsies: tissue ranging from "histologically normal" to that showing different levels of glial tumor involvement. J Immunol 1986; 136(11): 4054-62.

[61] Goldmann J, Kwidzinski E, Brandt C, Mahlo J, Richter D, Bechmann I. T cells traffic from brain to cervical lymph nodes via the cribroid plate and the nasal mucosa. J Leukoc Biol 2006; 80(4): 797-801. http://dx.doi.org/10.1189/jlb.0306176

[62] Calzascia T, Masson F, Di Berardino-Besson W, et al. Homing phenotypes of tumor-specific CD8 $T$ cells are predetermined at the tumor site by crosspresenting APCs. Immunity 2005; 22(2): 175-84. http://dx.doi.org/10.1016/j.immuni.2004.12.008

[63] Yang I, Han SJ, Kaur G, Crane C, Parsa AT. The role of microglia in central nervous system immunity and glioma immunology. J Clin Neurosci 2010; 17(1): 6-10. http://dx.doi.org/10.1016/j.jocn.2009.05.006 
[64] Albesiano E, Han JE, Lim M. Mechanisms of local immunoresistance in glioma. Neurosurg Clin N Am 2010; 21(1): $17-29$

http://dx.doi.org/10.1016/j.nec.2009.08.008

[65] Heimberger AB, Sampson JH. Immunotherapy coming of age: what will it take to make it standard of care for glioblastoma? Neuro Oncol 2011; 13(1): 3-13.

http://dx.doi.org/10.1093/neuonc/noq169

[66] Rolle CE, Sengupta S, Lesniak MS. Challenges in clinical design of immunotherapy trials for malignant glioma. Neurosurg Clin N Am 2010; 21(1): 201-14. http://dx.doi.org/10.1016/j.nec.2009.08.002

[67] Wei J, Barr J, Kong LY, et al. Glioblastoma cancer-initiating cells inhibit T-cell proliferation and effector responses by the signal transducers and activators of transcription 3 pathway. Mol Cancer Ther 2010; 9(1): 67-78.

http://dx.doi.org/10.1158/1535-7163.MCT-09-0734

[68] Lang R, Patel D, Morris JJ, Rutschman RL, Murray PJ. Shaping gene expression in activated and resting primary macrophages by IL-10. J Immunol 2002; 169(5): 2253-63.

[69] Mancino A, Lawrence T. Nuclear factor-kappaB and tumorassociated macrophages. Clin Cancer Res 2010; 16(3): 7849.

http://dx.doi.org/10.1158/1078-0432.CCR-09-1015

[70] Brantley EC, Benveniste EN. Signal transducer and activator of transcription-3: a molecular hub for signaling pathways in gliomas. Mol Cancer Res 2008; 6(5): 675-84. http://dx.doi.org/10.1158/1541-7786.MCR-07-2180

[71] Di Tomaso T, Mazzoleni S, Wang E, et al. Immunobiological characterization of cancer stem cells isolated from glioblastoma patients. Clin Cancer Res 2010; 16(3): 800-13. http://dx.doi.org/10.1158/1078-0432.CCR-09-2730

[72] Rosenberg SA, Lotze MT, Muul LM, et al. Observations on the systemic administration of autologous lymphokineactivated killer cells and recombinant interleukin-2 to patients with metastatic cancer. N Engl J Med 1985; 313(23): 148592.

http://dx.doi.org/10.1056/NEJM198512053132327

[73] Fyfe G, Fisher RI, Rosenberg SA, Sznol M, Parkinson DR, Louie AC. Results of treatment of 255 patients with metastatic renal cell carcinoma who received high-dose recombinant interleukin-2 therapy. J Clin Oncol 1995; 13(3): 688-96.

[74] Atkins MB, Lotze MT, Dutcher JP, et al. High-dose recombinant interleukin 2 therapy for patients with metastatic melanoma: analysis of 270 patients treated between 1985 and 1993. J Clin Oncol 1999; 17(7): 2105-16.

[75] Merchant RE, McVicar DW, Merchant LH, Young HF. Treatment of recurrent malignant glioma by repeated intracerebral injections of human recombinant interleukin-2 alone or in combination with systemic interferon-alpha. Results of a phase I clinical trial. J Neurooncol 1992; 12(1): 75-83. http://dx.doi.org/10.1007/BF00172459

[76] Colombo F, Barzon L, Franchin E, et al. Combined HSVTK/IL-2 gene therapy in patients with recurrent glioblastoma multiforme: biological and clinical results. Cancer Gene Ther 2005; 12(10): 835-48.

http://dx.doi.org/10.1038/sj.cgt.7700851

[77] Wolff JE, Wagner S, Reinert C, et al. Maintenance treatment with interferon-gamma and low-dose cyclophosphamide for pediatric high-grade glioma. J Neurooncol 2006; 79(3): 31521.

http://dx.doi.org/10.1007/s11060-006-9147-8

[78] Allen J, Packer R, Bleyer A, Zeltzer P, Prados M, Nirenberg A. Recombinant interferon beta: a phase I-II trial in children with recurrent brain tumors. J Clin Oncol 1991; 9(5): 783-8.

[79] Buckner JC, Schomberg PJ, McGinnis WL, et al. A phase III study of radiation therapy plus carmustine with or without recombinant interferon-alpha in the treatment of patients with newly diagnosed high-grade glioma. Cancer 2001; 92(2): 420-33.

http://dx.doi.org/10.1002/1097-

0142(20010715)92:2<420::AID-CNCR1338>3.0.CO;2-3

[80] Kikuchi T, Akasaki Y, Abe T, et al. Vaccination of glioma patients with fusions of dendritic and glioma cells and recombinant human interleukin 12. J Immunother 2004; 27(6): 452-9.

http://dx.doi.org/10.1097/00002371-200411000-00005

[81] Bogdahn U, Hau P, Stockhammer G, et al. Targeted therapy for high-grade glioma with the TGF-beta2 inhibitor trabedersen: results of a randomized and controlled phase Illb study. Neuro Oncol 2011; 13(1): 132-42. http://dx.doi.org/10.1093/neuonc/noq142

[82] Jaschinski $F$, Rothhammer $T$, Jachimczak $P$, Seitz $C$, Schneider A, Schlingensiepen $\mathrm{KH}$. The antisense oligonucleotide trabedersen (AP 12009) for the targeted inhibition of TGF-beta2. Curr Pharm Biotechnol 2011; 12(12): 2203-13.

http://dx.doi.org/10.2174/138920111798808266

[83] Hayes RL, Koslow M, Hiesiger EM, et al. Improved long term survival after intracavitary interleukin-2 and lymphokineactivated killer cells for adults with recurrent malignant glioma. Cancer 1995; 76(5): 840-52.

http://dx.doi.org/10.1002/1097-

0142(19950901)76:5<840::AIDCNCR2820760519>3.0.CO;2-R

[84] Itoh $K$, Sawamura $Y$, Hosokawa $M$, Kobayashi $H$. Scintigraphy with In-111 labeled lymphokine-activated killer cells of malignant brain tumor. Radiat Med 1988; 6(6): 27681.

[85] Kahlon KS, Brown C, Cooper LJ, Raubitschek A, Forman SJ, Jensen MC. Specific recognition and killing of glioblastoma multiforme by interleukin 13-zetakine redirected cytolytic $T$ cells. Cancer Res 2004; 64(24): 9160-6.

http://dx.doi.org/10.1158/0008-5472.CAN-04-0454

[86] Ahmed N, Salsman VS, Kew Y, et al. HER2-specific T cells target primary glioblastoma stem cells and induce regression of autologous experimental tumors. Clin Cancer Res 2010; 16(2): 474-85.

http://dx.doi.org/10.1158/1078-0432.CCR-09-1322

[87] van der Bruggen $\mathrm{P}$, Traversari C, Chomez $\mathrm{P}$, et al. A gene encoding an antigen recognized by cytolytic $T$ lymphocytes on a human melanoma. Science 1991; 254(5038): 1643-7. http://dx.doi.org/10.1126/science.1840703

[88] Rosenberg SA. Progress in human tumour immunology and immunotherapy. Nature 2001; 411(6835): 380-4. http://dx.doi.org/10.1038/35077246

[89] Ardon H, Van Gool SW, Verschuere T, et al. Integration of autologous dendritic cell-based immunotherapy in the standard of care treatment for patients with newly diagnosed glioblastoma: results of the HGG-2006 phase I/II trial. Cancer Immunol Immunother 2012. http://dx.doi.org/10.1007/s00262-012-1261-1

[90] Schneider T, Gerhards R, Kirches E, Firsching R. Preliminary results of active specific immunization with modified tumor cell vaccine in glioblastoma multiforme. J Neurooncol 2001; 53(1): 39-46.

http://dx.doi.org/10.1023/A:1011856406683

[91] Steiner $\mathrm{HH}$, Bonsanto $\mathrm{MM}$, Beckhove $\mathrm{P}$, et al. Antitumor vaccination of patients with glioblastoma multiforme: a pilot study to assess feasibility, safety, and clinical benefit. J Clin Oncol 2004; 22(21): 4272-81. http://dx.doi.org/10.1200/JCO.2004.09.038

[92] Ishikawa E, Tsuboi K, Yamamoto $\mathrm{T}$, et al. Clinical trial of autologous formalin-fixed tumor vaccine for glioblastoma multiforme patients. Cancer Sci 2007; 98(8): 1226-33. http://dx.doi.org/10.1111/j.1349-7006.2007.00518.x 
[93] Yang I, Han S, Parsa AT. Heat-shock protein vaccines as active immunotherapy against human gliomas. Expert Rev Anticancer Ther 2009; 9(11): 1577-82. http://dx.doi.org/10.1586/era.09.104

[94] See AP, Pradilla G, Yang I, Han S, Parsa AT, Lim M. Heat shock protein-peptide complex in the treatment of glioblastoma. Expert Rev Vaccines 2011; 10(6): 721-31. http://dx.doi.org/10.1586/erv.11.49

[95] Rosenberg SA, Yang JC, Restifo NP. Cancer immunotherapy: moving beyond current vaccines. Nat Med 2004; 10(9): 909-15. http://dx.doi.org/10.1038/nm1100

[96] Li G, Mitra S, Wong AJ. The epidermal growth factor variant III peptide vaccine for treatment of malignant gliomas. Neurosurg Clin N Am 2010; 21(1): 87-93. http://dx.doi.org/10.1016/j.nec.2009.08.004

[97] Gan HK, Kaye AH, Luwor RB. The EGFRvIII variant in glioblastoma multiforme. J Clin Neurosci 2009; 16(6): 748-54. http://dx.doi.org/10.1016/j.jocn.2008.12.005

[98] Heimberger AB, Archer GE, Crotty LE, et al. Dendritic cells pulsed with a tumor-specific peptide induce long-lasting immunity and are effective against murine intracerebral melanoma. Neurosurgery 2002; 50(1): 158-64; discussion 64-6.

[99] Sampson JH, Archer GE, Mitchell DA, Heimberger AB, Bigner DD. Tumor-specific immunotherapy targeting the EGFRvIII mutation in patients with malignant glioma. Semin Immunol 2008; 20(5): 267-75. http://dx.doi.org/10.1016/j.smim.2008.04.001

[100] Stupp R, Mason WP, van den Bent MJ, et al. Radiotherapy plus concomitant and adjuvant temozolomide for glioblastoma. N Engl J Med 2005; 352(10): 987-96. http://dx.doi.org/10.1056/NEJMoa043330

[101] Mine $T$, Sato $Y$, Noguchi $M$, et al. Humoral responses to peptides correlate with overall survival in advanced cancer patients vaccinated with peptides based on pre-existing, peptide-specific cellular responses. Clin Cancer Res 2004; 10(3): 929-37.

http://dx.doi.org/10.1158/1078-0432.CCR-1117-3

[102] Oka Y, Tsuboi A, Elisseeva OA, Udaka K, Sugiyama H. WT1 as a novel target antigen for cancer immunotherapy. Curr Cancer Drug Targets 2002; 2(1): 45-54. http://dx.doi.org/10.2174/1568009023334088

[103] Jarboe JS, Johnson KR, Choi Y, Lonser RR, Park JK. Expression of interleukin-13 receptor alpha2 in glioblastoma multiforme: implications for targeted therapies. Cancer Res 2007; 67(17): 7983-6.

http://dx.doi.org/10.1158/0008-5472.CAN-07-1493

[104] Eguchi J, Hatano M, Nishimura F, et al. Identification of interleukin-13 receptor alpha2 peptide analogues capable of inducing improved antiglioma CTL responses. Cancer Res 2006; 66(11): 5883-91.

http://dx.doi.org/10.1158/0008-5472.CAN-06-0363

[105] Saka M, Amano T, Kajiwara K, et al. Vaccine therapy with dendritic cells transfected with II13ra2 mRNA for glioma in mice. J Neurosurg 2010; 113(2): 270-9. http://dx.doi.org/10.3171/2009.9.JNS09708

[106] Bao S, Wu Q, McLendon RE, et al. Glioma stem cells promote radioresistance by preferential activation of the DNA damage response. Nature 2006; 444(7120): 756-60. http://dx.doi.org/10.1038/nature05236

[107] Schmitz M, Temme A, Senner V, et al. Identification of SOX2 as a novel glioma-associated antigen and potential target for T cell-based immunotherapy. Br J Cancer 2007; 96(8): 1293301.

$$
\text { http://dx.doi.org/10.1038/sj.bjc.6603696 }
$$

[108] Ueda R, Kinoshita E, Ito R, Kawase T, Kawakami Y, Toda M. Induction of protective and therapeutic antitumor immunity by a DNA vaccine with a glioma antigen, SOX6. Int $\mathrm{J}$ Cancer 2008; 122(10): 2274-9. http://dx.doi.org/10.1002/ijc.23366 